\title{
A Reportagem Jornalística e a Memória - Histórias em Movimento
}

\section{La Información Periodistica y la Memoria - Moviendo Historias}

\author{
Ma. Jerusa de Oliveira Michel${ }^{1}$; Ma. Margareth de Oliveira Michel \\ 1 jerusa.michel@gmail.com, Universidade Federal de Pelotas; \\ 2 margareth.michel@gmail.com, Universidade Federal de Pelotas
}

\begin{abstract}
Resumo
O trabalho analisa a partir de diferentes campos do conhecimento: antropologia, etnografia, etnicidade, território, história e memória em suas diversas abordagens, e o gênero jornalístico reportagem, a perspectiva de construção de conhecimento interdisciplinar, identificando os pontos de convergência entre os campos. Utiliza metodologia etnográfica/interdisciplinar, focando o trabalho da jornalista Eliane Brum à luz do referencial teórico construído.
\end{abstract}

Palavras-Chave: Jornalismo, Reportagem, Memória, Parteiras, Identidades

\section{Resumen}

El trabajo analiza desde diferentes campos del conocimiento: la antropología, la etnografía, la etnia, territorio, historia y memoria en los diversos enfoques, y de la entrada de género periodístico, la perspectiva de la construcción de conocimiento interdisciplinario, la identificación de los puntos de convergencia entre los campos. Utiliza la metodología etnográfica / interdisciplinaria, centrándose en el trabajo de la periodista Eliane Brum a la luz del marco teórico construido.

Palabras clave: Periodismo, Informes, Memoria, Matronas, Identidades.

\section{Introdução}

Este trabalho aborda a participação do jornalismo, por meio de reportagens, e a preservação da memória social. O interesse pelo tema se deve ao fato de que ao atuar na área de comunicação, e mais especificamente ao produzir reportagens jornalísticas ocorreu a percepção de que o profissional ao registrar fatos, contar histórias, de certa forma, contribui para a perpetuação daquilo que registrou.

É histórica a constatação de que existe no ser humano e nos grupos sociais o desejo de manter vivas as lembranças de acontecimentos marcantes e até mesmo de fatos cotidianos. Em função disso, desde os tempos primitivos técnicas de comunicação foram desenvolvidas com a finalidade de contribuir com a perpetuação do tempo e junto com técnicas capazes de desenvolver a memória (desenhos/imagens gravadas nas paredes das cavernas, inscrições em pedra, papiros, pergaminhos, etc) desenvolveu-se também a linguagem como instrumento de 
propagação das lembranças, representações e histórias, que propiciou ao homem a possibilidade de construir e registrar sua trajetória. (RIBEIRO, 2012)

Com o surgimento da escrita, as forma de armazenar informações e remomorar os fatos mudaram, pois o homem letrado foi capaz de reconstruir de forma retrospectiva, o tempo da história. Na perspectiva de Lévy (1993), a memória passou a apresentar-se disponível, catalogada e comparável, o saber deixa de ser apenas aquilo que é útil no dia-adia, aquilo que constitui o sujeito enquanto ser humano, com identidade própria, membro de uma comunidade, e tornou-se um objeto suscetível de análise e exame.

Halbwacks (1990) chama a atenção para a maneira pela qual a escrita foi encarada pelo homem: maneira única de se conservar lembranças porque "as palavras e os pensamentos morrem, mas os escritos permanecem" (HALBWACHS, 1990, p. 80). A partir da importância da narrativa escrita na construção da história de uma sociedade, o valor do jornalismo impresso como documento histórico, desde o surgimento da imprensa, no século XVIII, não pode ser ignorado, mesclando-se com com o cotidiano dos grupos sociais. Desde então tornou-se marcante a necessidade das pessoas de registrarem a vida cotidiana como uma das formas de manutenção da memória. Nesse contexto, a memória jornalística marca "a entrada em cena da opinião pública [...] que constrói também a sua própria história" (Le Goff, 2003, p. 461).

O jornalismo transforma a realidade apreensível em relato, tornando-se peça fundamental no registro de acontecimentos e isso lhe confere função histórica na sociedade. Na visão de Tranquina (1999), o jornalismo é entendido como uma prática social, que estabelece relações com o mundo material e com o mundo simbólico dos indivíduos, que acontecem enquanto história e linguagem. História porque são relações constituídas a partir das exterioridades do jornalismo, que se encontra inserido dentro do processo de produção, transformação e manutenção da sociedade. Linguagem porque são relações constituídas também a partir do modo de quem faz.

Essa mescla entre a produção jornalística com a história e a memória, num processo imbricado com a prática e o cotidiano dos grupos sociais, lidando com o material concreto e simbólico dos indivíduos e grupos sociais, como já dito, é o objeto de estudo desse trabalho e para a melhor compreensão da proposta serão abordados tópicos referentes ao jornalismo,com atenção especial ao gênero reportagem, finalizando com o estudo de caso da reportagem "A floresta das parteiras" da jornalista e escritora Eliane Brum. 


\section{Sobre o Jornalismo e o Gênero Reportagem}

O campo jornalístico começou a ganhar forma nas sociedades ocidentais, durante o séc. XIX, com o desenvolvimento do capitalismo e, ao mesmo tempo, de outros processos que incluem a industrialização, a educação em massa, o processo tecnológico e a emergência da imprensa. O jornalismo que conhecemos hoje tem suas raízes no século XIX, e de acodo com Traquina (2005), foi durante este período que se verificou o desenvolvimento da imprensa. Foi então que "As trocas de informações atingiram intensidade e amplitude antes difíceis de imaginar. E a notícia, antes restrita e controlada pelo estado e pela Igreja, tornou-se bem de consumo essencial" (LAGE, 1999, p 8). Além disso, a expansão dos jornais permitiu a criação de novos empregos e um número crescente de pessoas passou a dedicar-se a uma atividade.

\footnotetext{
Este novo paradigma será a luz que viu nascer valores que ainda hoje são identificados no jornalismo: as notícias, a procura da verdade, a independência dos jornalistas, a exatidão, e a noção do jornalismo como um serviço ao público - uma constelação de idéias que dão forma ao emergente "pólo ideológico" do campos jornalístico (TRAQUINA, 2005, p.34).
}

Por essas dimensões, podemos destacar que o jornalismo é um ato de transmitir conhecimento presente nos últimos séculos, sendo que suas doutrinas, leis, e formas de relacionamentos estiveram presentes na formação de muitos povos e civilizações e, em função do empenho em noticiar os fatos, a história da humanidade segueregistrada, comprovando o valor que possui a cobertura de notícias e acontecimentos.

Beltrão e Quirino (1986), Dines (1996), Lage (1999), e Marques de Melo (2012), entre outros, entendem que o jornalismo tem como função básica informar a sociedade, averiguando de que forma os fatos acontecem, transmitindo-os para a população, constituindo-se numa atividade que acompanha a sociedade há várias gerações, proporcionando possibilidades de difusão de conhecimentos e de informações numa escala antes inimaginável. "A sociedade se enriquece com a experiência do passado, o relato do presente e as especulações e projetos do homem para o futuro". (BELTRÃO, QUIRINO, 1986, p. 22).

O jornalismo também tem função importante na formação da cultura, pois não é possível existir uma sociedade bem informada culturalmente se não receber informações - há uma relação entre o jornalismo e a sociedade: através de notícias atuais e apuradas, há uma contribuição com a formação cultural da sociedade. Karam (1997) coloca que, a informação é importante não apenas para que saibamos aquilo que acontece nas distintas regiões do mundo 
e nos posicionarmos diante de culturas, comportamentos, política, economia, etc., mas também para que saibamos o que ocorre no mundo.

A sociedade representa, em essência, mais do que uma associação de indivíduos; constitui uma comunidade de ação e comunicação, cuja existência é necessária tanto para o desenvolvimento da vida humana, quanto para o desenvolvimento de uma vida social com sentido.

A sociedade se confunde em sua estrutura com a cultura, na medida em que representa um fenômeno gerado simbolicamente pela comunicação. A comunicação é o mecanismo de coordenação da interação social, torna possível o consenso entre as pessoas. Em função disso, não pode ser reduzida à pura e simples transmissão de experiências, consiste no processo pelo qual os sujeitos têm uma experiência comum da realidade, constroem seu mundo como coletividade (RÜDIGER, 1998, p. 37).

A sociedade deve ser vista como formada por comunidades simbólicas de participação, que fornecem sentido às ações humanas e à realidade social. O jornalismo é fruto do ser humano e de suas necessidades. As notícias só existem, em função das pessoas e de seus cotidianos, a maneira com a qual a ética e a moral conduzem suas atitudes, servem de balança para julgar o que é certo e errado. A sociedade é composta por grupos de pessoas, únicas e distintas, no entanto, ao olhar de um jornalista suas histórias são mais do que relatos subjetivos, são notícias, são acontecimentos.

Assim, o jornalismo pode ser entendido como tendo um "papel socialmente legitimado para produzir construções da realidade que são publicamente relevantes" (ALSINA, 1996, p. 18), ou seja, ao jornalista é delegada a competência para recolher os acontecimentos e temas importantes e atribuir-lhes sentido, firmando, com a sociedade, um "acordo de cavalheiros", “contrato fiduciário" social e historicamente definido (TRAQUINA, 1999, p. 168).

Por outro lado, os processos de formação da identidade e do acervo social do conhecimento são processos que acontecem simultaneamente na sociedade; é disso que a sociedade vive, e estar em sociedade significa participar da dialética desse processo. Ser um ser social é fazer parte desse processo de interiorizar, subjetivar e exteriorizar, objetivar, onde as estruturas sociais definem tipos de identidade. (BERGER e LUCKMANN, 1976) Mas é preciso destacar que embora esse processo de construção social dependa dos conteúdos e da prática discursiva do jornalismo, deve-se ficar atento para não incorrer no erro de imaginar essa construção sem a participação ativa do público, nas diversas interações em que os indivíduos tomam parte no dia-a-dia. 
Rudiger(1998) afirma que a comunicação, em especial o jornalismo, é um mecanismo de interação social que torna possível consensos entre as pessoas. "Em função disso, não pode ser reduzida à pura e simples transmissão de experiências, consiste no processo pelo qual os sujeitos têm uma experiência comum da realidade, constroem seu mundo como coletividade" (RÜDIGER, 1998, p. 37). Em decorrência disto, principal função do jornalismo é revelar os fatos com a máxima neutralidade, portanto, os princípios da imparcialidade, interpretação e objetividade são fundamentais para se atingir esse objetivo.

No jornalismo, os fatos são retratados por diversos olhares e através de diferentes gêneros, em que o jornalista, ao transmitir o fato para o público interessado, o descreve de acordo como o viu e ouviu, procurando atingir, por meio da clareza e da escolha das palavras, a melhor estrutura morfológica, sintática, e principalmente, buscando a objetividade. Com relação aos gêneros jornalísticos existem várias classificações. Aqui será utilizada a classificação feita por Beltrão, por atender a critérios funcionais, de acordo com as funções que os textos desempenham em relação ao leitor, que seriam informar, explicar ou orientar. A partir dessas informações, ele propõe três categorias básicas: jornalismo informativo (notícia, reportagem), jornalismo interpretativo (reportagem em profundidade), e jornalismo opinativo (editorial, artigo, crônica, opinião ilustrada, opinião do leitor).

O jornalismo interpretativo é uma forma de fazer jornalístico extremamente rico na abordagem informativa, pois, "ao inquirir sobre as causas e origens dos fatos, busca também a ligação entre elas e oferece a explicação da sua ocorrência". (DINES, 2009, p. 110) A reportagem é um gênero jornalístico privilegiado. Para Noblat (2004), "notícia é o relato mais curto de um fato. Reportagem é o relato mais circunstanciado". A história é contada de acordo com a subjetividade de cada um, porém na hora de se escrever a história, os valores básicos como a veracidade e a objetividade dos fatos deverão ser mantidos.

Sodré e Ferrari (1986) identificam as principais características de uma reportagem: predominância da forma narrativa, humanização do relato, texto de natureza impressionista e objetividade dos fatos narrados. Os autores destacam que conforme o assunto ou o objeto em torno do qual gira a reportagem, alguma dessas características poderão aparecer com maior destaque, mas é sempre necessária a presença da forma narrativa.

A reportagem é, portanto, um gênero que precisa ser bem preparado, que necessita de um grande preparo, físico e emocional, porque geralmente toma tempo na seleção das melhores fontes, leitura de documentos, conversa com os diferentes protagonistas e personagens envolvidos na história, exigindo que seja captado o ambiente onde ocorrem ou ocorreram os acontecimentos. 


\subsection{A questão da memória}

Memória é um tema que está presente em várias áreas de estudo no mundo contemporâneo e é vista a partir de diferentes olhares. Do ponto de vista biológico, memória refere-se a tudo que envolve os processos mentais e as muitas informações no cérebro, tais como idéias, imagens e diferentes dados, tudo que por diferentes motivos se destaque entre os registros de acontecimentos passados. De acordo com Izquierdo (2014) "Sem memória não há vida. É possível, inclusive, dizer que a vida é uma sequência de memórias".

A memória é importante para a vida ds grupos sociais porque é o armazenamento e lembrança daquilo que é adquirido por meio da experiência, dessa forma a aquisição de memórias é aprendizado.(IZQUIERDO, 1989). O autor cita Marshall (1988) afirmando que há 2.000 anos atrás, Aristóteles já dizia que tudo que está no intelecto esteve antes nos sentidos, e considera que não há memória sem aprendizado nem aprendizado sem experiências.

Se por um lado é reconhecida a importância da existência da memória relacionada à vida, por outro, há quase um consenso de que a sociedade contemporânea é 'uma sociedade sem memória' seja por conta dos aparatos tecnológicos ou em função das muitas e rápidas mudanças que ocorrem, gerando um movimento contínuo e fluído (BAUMAN, 2011) onde pelo excesso de informações há uma necessidade cada vez maior de dispositivos de armazenamento de informações (NORA, 2000).

$\mathrm{Na}$ visão de muitoa autores, ocorre no mundo contemporâneo, uma 'falta de memória', fenômeno que aponta para várias perspectivas: nossa sociedade comumente é designada 'sociedade sem memória', devido às mudanças rápidas existe uma "fluidez" que exige movimento constante, com a utilização das 'tecnologias contemporâneas' remete a uma constante atualização de instrumentos e conhecimentos, entre outras. Em decorrência das muitas atividades que cada pessoa desenvolve, há pouco ou nenhum tempo para o registro das suas experiências e histórias de vida.

Há um descompasso entre as gerações de 'jovens' e 'velhos' marcado pelas mudanças profundas, aceleradas e contínuas, as sociedades ocidentais descartam objetos e pessoas como nunca antes na história, desenvolvendo um 'apetite' insaciável por novidades. (BAUMAN, 2011, p. 112). Mas o sociológo, apesar de suas constatações coloca: “A vida é maior que a soma de seus momentos.” Esta afirmativa de Bauman remete à importância da manutenção dos relacionamentos entre pessoas e grupos sociais e das narrativas da história e da manutenção de sua memória, pois embora reconhecendo as dificuldades da vida numa 
sociedade fragmentada, que estimula o individualismo e a fragilidade dos laços humanos, ele acredita na possibilidade de mudança.

As 'tecnologias contemporâneas' remetem a uma constante mudança e atualização de instrumentos e conhecimentos, que segundo Nora (2000), levam a uma necessidade constante de obter dispositivos para armazenar dados, memória. Para Nora, devido à fluidez e rapidez da nossa experiência cotidiana, o que está mudando é a relação que os indivíduos mantêm com o passado, experiência que precisa ser revista e revisitada, pois são as narrativas de memória que oferecem a possibilidade de um retorno ao passado.

Os teóricos concordam com a premissa de que tanto a história oral quanto a memória são essenciais para a construção tanto das identidades pessoais quanto coletivas, especialmente na sociedade contemporânea, na qual as identidades são tão fluidas, fragmentadas, descentradas, ou "líquidas", Bauman (2005) e Hall (2005). Em vista disso, deve ser levada em conta a posição de Hall quando ele coloca que "nossa identidade, tenha ela a forma que tiver, é uma história sobre nós mesmos, ou em última análise, uma 'narrativa do eu' "' (HALL, 2005, p.12), por certo construída com a ajuda de nossa memória, por meio da nossa história de vida.

Fazendo um contraponto com a sociedade moderna, "tão líquida", as parteiras do Amapá fazem parte de uma comunidade que traz consigo memórias e experiências de vida muitas alegres, muitas sofridas - de uma das atividades mais tradicionais do Brasil, a que se ocupa de trazer os seres humanos ao mundo por meio do nascimento, uma atividade baseada na simplicidade, onde as próprias parteiras desenvolvem suas artes e seus instrumentos de trabalho criando uma cultura e uma identidade própria.

Para entender melhor esta questão, é importante contextualizarmos o jornalismo e sua relação com a temática, esclarecendo que no processo de construção das identidades sociais, no fluxo das interações, o jornalismo como um todo ocupa um papel central. Pierre Nora fala do papel dos meios de comunicação de massa na produção dos acontecimentos históricos, afirmando que "Imprensa, rádio, imagens não agem apenas como meios dos quais os acontecimentos seriam relativamente independentes, mas como a própria condição de sua existência.”(Nora, 1988, p. 181). A partir da proposição do autor, que a memória constitui uma dimensão primordial na constituição das identidades, envolvendo práticas narrativas e administração do real por meio das práticas discursivas, compreende-se que o jornalismo é um elemento importante desse processo. 
O jornalismo, no arcabouço da mídia, é uma atividade que produz diariamente registros utilizados como fonte de informação num sentido amplo e, especialmente, de marcação no sentido histórico. De acordo com Letícia Cantarela Matheus:

\begin{abstract}
As marcas do tempo são especialmente sensíveis nos jornais, localizando o leitor num "lugar" na duração. O consumo diário das narrativas jornalísticas fornece um forte parâmetro espaço-temporal. [...] A marcação do tempo foi se tornando função essencial dos jornais, a ponto de lhes ser dada credibilidade para datá-lo (MATHEUS 2010, p.2-3).
\end{abstract}

Identidade, memória e jornalismo são, a partir dessa perspectiva, concepções tomadas como possuidoras de uma relação direta, isso porque o jornalismo (como mídia ou segmento da comunicação de massa) mantém relações claras com a História, caracterizandose como ferramenta de compreensão e recuperação do passado. Em nenhuma outra época, a produção de conhecimentos foi tão intensa como nos dias de hoje registrando os fatos, o cotidiano, a própria história e nem sua aplicação assumiu papel tão importante na produção jornalística, seja na especificidade da notícia ou da reportagem enquanto um "documento" histórico, referência necessária para a compreensão da relação que se estabelece entre a "memória jornalística" e a "memória social";

[...] podemos constatar que a construção temporal envolvida no jornalismo não se articula tanto à atualidade em si, mas sim, a um presente da ação social, como sublinha Franciscato (2003, p. 285). E isso significa assumir, de uma maneira ampla, que o presente é uma construção social, de forma que os conteúdos compartilhados pelo jornalismo dizem respeito a uma experiência temporal discursiva relacionada a "um sentido partilhado socialmente resultante da atuação de atores sociais no ambiente - uma construção, por indivíduos e instituições, de concepções e produtos simbólicos ou de estruturas carregados de uma temporalidade do presente" (FRANCISCATO, 2003, p. 285). [...] Esse presente social deve ser entendido, portanto, como "um tempo de referência da ação coletiva", de forma que o jornalismo, ao rodear a sociedade de um presente social contínuo, oferece um tipo de conteúdo que é "bastante novo para que nos impressione e bastante velho para que possamos conhecê-lo e comentá-lo" (GOMIS apud FRANCISCATO, 2003, p. 336).

A memória, em nosso tempo ou no tempo de nossos ancestrais, está entre os elementos formadores dos objetos culturais e sociais. É através das narrativas do presente, observadas no jornalismo que muitas vezes podemos analisar a prática de armazenar, preservar e reconstruir versões de passados comuns, indicados em padrões e tendências, em processos de composição e recuperação de informações jornalísticas. A sociedade se vê representada por meio da prática jornalística, que é "memória em ato, enraizada no concreto, 
no espaço, na imagem, no objeto, presente vivido e transformado em notícia que amanhã será passado relatado, constantemente recuperado" (PALACIOS, 2010).

Nessa perspectiva, o Jornalismo também é compreendido como importante "Lugar de Memória" (NORA, 1993; 1997), caracterizando-se por ser portador de uma realidade construída a partir dos acontecimentos, que é apresentada como verídica e imparcial, ocupando espaço destacado no arquivamento e na produção da memória contemporânea (RIBEIRO, 1995; BARBOSA, 1996; ENNE, 2004).

É por meio do jornalismo que são registrados fatos, testemunhos e padrões de comportamento, os quais podem caracterizar diferentes épocas e momentos da história, desta forma, os jornalistas podem ser considerados como "Agentes de Memória" que muitas vezes não são reconhecidos por eles próprios nem pelos estudiosos da memória.Em seu artigo, “Why memory's work on journalism does not reflect journalism's work on memory" ', Zelizer explica que o trabalho jornalístico permite apresentar o passado, oferecendo ao mesmo tempo, pontos de comparação e oportunidades de fazer analogias, ao mesmo tempo em que dá nova roupagem a eventos anteriores. Ao incluirem o passado nas suas narrativas, os jornalistas apresentam clararamente a importância do passado na produção de sentido do presente, e por isso eles se tornaram “Agentes de Memória” (ZELIZER, 2008).

Por intermédio da informação jornalística ocorre o vínculo com o passado (no qual está presente a ilusão de que o conteúdo está relacionado ao que era melhor, mais original) e que permite à memória encontrar associações que auxiliam na compreensão dos acontrecimentos do presente em seu contexto, com suas interligações, coerentes com os acontecimentos de ontem, e que tornam o jornalismo legítimo (BERKOWITZ, 2011).

O jornalismo na sociedade contemporânea apresenta-se como formador de opinião e de visões acerca do real. Muitos autores, entre os quais os citados anteriormente no texto, tem buscado mostrar como os meios de comunicação de massa, de forma especial o jornalismo, ocupam um lugar importante como formadores e mantenedores/armazenadores da memória social. Nesse caso, os jornais podem ser pensados, segundo Nora "como construtores e/ou legitimadores de lugares de memória" (Ribeiro, 1996).

Conforme Pollak (1992), a memória é um elemento constituinte do sentimento de identidade, tanto individual como coletivo, construído no conjunto pelas experiências e vivências do indivíduo e de seu grupo. Pode ser submetida a transformações constantes, transmite a cultura local herdada e é constituída por acontecimentos vividos socialmente.

\footnotetext{
${ }^{1}$ Tradução da autora: "Por que o trabalho de memória no jornalismo não reflete o trabalho de jornalismo na memória"
} 
Nessa ótica, são três os elementos que servem de apoio à memória: os acontecimentos vividos, as pessoas e os lugares. E, são estes os elementos responsáveis pelo estabelecimento dos laços afetivos entre as pessoas. Para o autor, a memória é seletiva, pois nem todos os fatos ficam registrados e os indivíduos só têm recordações dos momentos a que dão importância e que, por alguma razão, ficaram marcados subjetivamente. Ainda na perspectiva de Pollak (1992), os acontecimentos históricos são auxiliares na nossa memória; não desempenham outro papel, senão as divisões do tempo assinaladas em relógio ou determinadas pelo calendário. Um indivíduo para lembrar seu passado tem que se remeter às lembranças dos outros, que se constituem em pontos de referência, onde estão fixados pela sociedade. Desta forma, a memória coletiva envolve sentimentos de pertença e identidade, já que ela é sempre dependente das interações e dos grupos sociais.

\subsection{A reportagem "A Floresta das Parteiras"e sua Análise}

Este estudo caracteriza-se pela sua interrelação com diferentes campos sociais e pela interdisciplinaridade ao abordar as questões relativas ao jornalismo/reportagem, identidade, e memória contidos na reportagem "A Floresta das Parteiras", de Eliane Brum. Além dos conceitos já abordados, em sua análise levará também em conta o pensamento relativo à cultura do grupo no qual se encaixam as parteiras da floresta, na Amazônia.Voltamo-nos então para a figura da parteira, mãe de pegação, na maioria dos casos, negra ou índia e pobre. Eliane Brum, em "As Parteiras da Floresta", vem nos falar exatamente destas mulheres. Ela as descreve como mulheres extremamente sábias sem que para isso, seja preciso conhecer as letras do alfabeto. Seu texto inicia narrando uma parte da história destas mulheres.

\footnotetext{
Elas nasceram do ventre úmido da Amazônia, no extremo norte do Brasil, no Estado esquecido do noticiário chamado Amapá. O país não as escuta porque perdeu o ouvido para os sons do conhecimento antigo, para a música de suas cantigas. Muitas não conhecem as letras do alfabeto, mas são capazes de ler a mata, os rios e o céu. Emergiram dos confins de outras mulheres com o dom de pegar menino, adivinham a vida que se oculta nas profundezas. (BRUM, 2008, p.19)
}

Caco Barcelos, jornalista com larga experiência profissional, escreve a apresentação do livro de Eliane Brum - O Olho da Rua. A posição dele acerca da escrita e dos métodos de Brum é importante pela visão que possui acerca da prática profissional da jornalista: "A imprensa simboliza a liberdade, não é só uma atividade profissional. O jornalista, o repórter tem o dever de contar os episódios na medida em que eles forem acontecendo", ele disse em entrevista à Amilton Pinheiro, do Portal de Comunicação da UOL. Por esta posiçãopessoal, 
ao se referir à forma como a autora encara o jornalismo e o gênero reportagem, ele escreveu no prefácio:

Reportagem, para Eliane, é um ato de entrega, de envolvimento intenso entrequem fala e quem escuta, por meio de uma relação preciosa de confiança mútua entre repórter e personagem. [...] São práticas de conduta simples, mas simbolicamente corajosas por se oporem, nestes tempos, à corrente dominante nas redações brasileiras, reféns da arrogância e de maniqueísmos. [...] "Muito jornalista experiente escorrega porque presume demais. E presume a partir de seus preconceitos, de sua visão de mundo, de sua vida cotidiana numa realidade muito diferente..." (BARCELOS, 2008, p. 10-11)

Sobre Brum (2008) e sua metodologia de construção da reportagem Barcelos (2008) afirma:

Os métodos rigorosos de pesquisa da autora representam, para meu entusiasmo, o avesso da dinâmica tecno-burocrática predominante. Apurar por e-mail, por telefone, por intercâmbios eletrônicos de informação, além de excluir da pesquisa a maioria da população, que não tem acesso a essas tecnologias, elimina o melhor da prática jornalística: ouvir de perto, ao vivo, de preferência com os pés envolvidos "na lama dos acontecimentos". A reportagem é a arte da escuta. Para Eliane Brum, é muito mais do ouvir. [...] ela exercita com esmero o seu dom de ouvinte, que abrange por ofício a captação do tom e do ritmo das palavras e do silêncio. É o seu jeito de aproveitar ao máximo o privilégio dos repórteres: o de ver primeiro, o de entrar nas casas, o de ouvir narrativas de vidas, do parto à vivência da morte, para depois transmitir aos outros. (BARCELOS, 2008, p. 11)

Sobre si mesma, Brum (2008, p.11), comenta "Como repórter e como gente eu sempre achei que mais importante do que saber perguntar era saber ouvir. Eu não arranco nada. Só me comprometo a ouvir, a escutar de verdade, sem preconceitos" E continua, afirmando:

Ser repórter é algo profundo, definitivo, do que sou. Todo meu olhar sobre o mundo é mediado por um amor desmedido pelo infinito absurdo da realidade. E pela capacidade de cada pessoa de reinventar a si mesma, dar sentido ao que não tem nenhum. [...] Em cada rua do mundo, seja de floresta ou de concreto, busco aquilo que faz tantos brasileiros andarem pelo mapa, às vezes descalços. Aquilo que move tantos de nós a ancorar no dia seguinte - e um dia depois do outro. Meu ofício é encontrar o que torna a vida possível apesar de tudo, a delicadeza na brutalidade do cotidiano, a vida na morte. (BRUM, 2008, p.13-14)

A Floresta das Parteiras é a primeira das oito reportagens do livro "O Olho da Rua", que Brum lançou em 2008, e que foi também publicada na revista Época. O texto fala que:

É sabedoria que não se aprende, não se ensina nem mesmo se explica. Acontece apenas. Esculpidas por sangue de mulher e água de criança, suas mãos aparam um pedaço ignorado do Brasil. O grito ancestral ecoa do território empoleirado no cocuruto do mapa para lembrar ao país que nascer é natural. Não depende de engenharia genética ou operação cirúrgica. Para as parteiras, que guardaram a 
tradição graças ao isolamento geográfico do berço, é mais fácil compreender que um boto irrompa do igarapé para fecundar donzelas que aceitar uma mulher que marca dia e hora para arrancar o filho à força. (BRUM, 2008, p. 19)

Assim, as mãos dessas mulheres fazem do estado do Amapá a região com o maior número de partos normais no Brasil das cesarianas. Ofício repassado entre gerações, onde muitas mulheres de uma mesma famíliaabraça o ofício de parteira, ou como elas mesmas se autodenominam, mãe de pegação, a maioria, segundo dados de organizações que apoiam essas parteiras, está na região norte e nordeste, onde os níveis de pobreza são maiores. A estimativa é de que 60 mil mulheres atuem como parteiras no Brasil, concentrando-se no interior do país, comunidades quilombolas e indígenas.

\begin{abstract}
Encarapitadas em barcos ou tateando caminhos com os pés, a índia Dorica, a cabocla Jovelina e a quilombola Rossilda são guias de uma viagem por mistérios antigos. Cruzam com Tereza e as parteiras indígenas do Oiapoque, onde já começou o Brasil. Unem-se todas pela trama de nascimentos inscritos na palma da mão. "Pegar menino é ter paciência", recita a caripuna Maria dos Santos Maciel, a Dorica, a mais velha parteira do Amapá. Aos 96 anos, mais de 2 mil índios conheceram o mundo pelas suas mãos pequenas, quase infantis. Dorica - avó, mãe, madrinha - nem mesmo gostaria de possuir o "dom". "O dom é assim, nasce com a gente. E não se pode dizer não", explica. "Parteira não tem escolha, é chamada nas horas mortas da noite para povoar o mundo." (BRUM, 2008, p.28)
\end{abstract}

Para estas parteiras é praticamente impossível entender como uma mulher escolhe arrancar seu filho a força, através de uma cesariana, com data e horário agendado. Segundo dados do Ministério da Saúde, 24\% dos 2,6 milhões de partos que acontecem no Brasil são cirúrgicos quando apenas $5 \%$ a $10 \%$ destes partos necessitam de cirurgia. Nadando contra esta corrente, o Amapá traz quase $90 \%$ de sua população ao mundo através das mãos de aproximadamente 752 "pegadoras de menino", sendo considerado o estado brasileiro recordista em partos normais. Transcrevo abaixo, algumas passagens do texto "Parteiras da Floresta" de Eliane Brum, onde ela descreve de forma quase poética a vida destas parteiras.

Através destas falas é possível perceber claramente as condições destas mulheres

São pobres as parteiras. Muitas nem dentes têm. Outras só comem farinha de tapioca. Ajudar a humanidade a vir ao mundo nunca lhes rendeu nenhum tostão. "O que eu mais queria nesta minha vida era uma cama bonita", suspira Cecília Forte, 66 anos, que nunca conheceu outro pouso para o corpo que não fosse uma rede de algodão. Quando a fome aperta o ventre, o coração capitula, ameaça parar. (BRUM, 2008, p. 32)

Medina (1986), Piza (2003), Marques de Melo (1994, 2003), entre outros, afirmam que os textos jornalísticos têm como funções informar, explicar ou orientar os leitores, e se 
enquadram em categorias básicas, como a caracterizada pelo jornalismo informativo (nota, notícia, reportagem, e entrevista), ou a em que se enquadra o jornalismo interpretativo (reportagem em profundidade), características encontradas no texto da reportagem de Brum. Também encontramos na reportagem fontes iconográficas, importantes na linguagem jornalísticas, pois na perspectiva de Kossoy (2005, p. 50), “dentre as diferentes formas de informação transmitidas pela mídia, as imagens, em geral, se constituem num dos sustentáculos da memória”. Lima (2012) afirma que

Quando se fala em memória, estamos trabalhando com pessoas, representações sociais, tempos, espaços, significados, valores culturais, sentimentos individuais e coletivos. Essas memórias sejam individualizadas e/ou coletivas constituem e organizam a história juntamente com as práticas culturais de um determinado local, construindo suas identificações conforme as relações com o outro. (LIMA, 2012, p. 145)

Ao descrever as parteiras, Brum perpassa por todos esses elementos, identificando nas parteiras e em seus relatos identidades e representações sociais, cujos significados individuais e coletivos, não só organizam sua prática cultural, mas estão presentes na memória do gupo. A memória, para Le Goff (2003), é expressa de forma tanto individual quanto coletiva. Cada sujeito revela uma subjetividade, manifestada tanto em alguma coisa representativa do passado e quanto a partir do momento que suas lembranças e experiências são compartilhadas pelos diferentes grupos sociais, quando a memória se torna coletiva. É então que a memória contribui para sejam apropriados saberes estabelecidos por experiências de grupos sociais, permitindo que se forme um elo entre memória e narrativa.

Ao abordar o relato do passado em sua reportagem, Brum apresenta sua importância na produção de sentido do presente por meio de testemunhos e padrões de comportamento, e conforme o refencial teórico ao caracterizar diferentes momentos da história, pode ser considerada como 'agente de memória'. Também são encontrados na reportagem de Brum os elementos que estão presentes no sentimento de identidade e que servem de apoio à memória: os acontecimentos vividos, as pessoas e os lugares, e que envolvem sentimento de pertença à memória coletiva em decorrência das interações e dos grupos sociais.

\section{Metodologia}

A metodologia de estudo utilizada neste trabalho baseou-se na pesquisa bibliográfica, tendo como universo da análise as publicações existentes em material impresso (livros, revistas, trabalhos de conclusão) e em meio eletrônico (Internet). Utilizou-se o Método 
Hipotético Dedutivo, que permite através das hipóteses formuladas, levantar questões que possam servir de base para a fundamentação teórica e a comprovação do tema proposto.

\section{Considerações Finais}

Nestes trechos do texto da jornalista fica clara a origem destas mulheres quando as descreve como "a índia Dorica, a cabocla Jovelina e a quilombola Rossilda". Fala ainda das "parteiras indígenas do Oiapoque". Seguindo através do texto de Brum, ela nos fornece a descrição da cabocla Jovelina, que aos 77 anos é a parteira mais afamada de Ponta Grossa do Piriri no Amapá e relata seu estado de pobreza ao relatar que a parteira mora em um casebre, fala também da "negra, negríssima" Rossilda, mulher quilombola, ressaltando a questão da sua cor, o que pode nos dar uma ideia de que sua vida jamais foi fácil, percebe-se aqui a construção da identidade e da cultura dessas mulheres, conforme os parâmetros dos autores do referencial teórico.

Construir uma reportagem é contar uma história, é ter o privilégio de conviver com pessoas que são diferentes de nós, de ver primeiro, de entrar em suas casas, de ouvir seus relatos, sua história, e depois transmiti-los aos outros. O texto em questão está repleto das falas destas mulheres, e é através destas falas que a jornalista o constrói, respeitando linguagem utilizada pelas parteiras. Ser jornalista é muito mais do que simplesmente narrar os fatos de forma objetiva e neutra, apurando os fatos do dia para que sejam entregues a sociedade o mais rápido possível. É possível que se faça um jornalismo onde o mais importante seja ouvir não aquilo que se quer perguntar, mas sim aquilo que a pessoa quer nos dizer.

Olhando o jornalismo e a construção das reportagens a partir desta perspectiva, pode-se afirmar que o jornalismo como prática pode ser aliado das ciências sociais, utilizando suas técnicas e metodologias para apurar os fatos e averiguar as verdades, registrando sua história, e que pode sim se constituir de valioso instrumento de construção de história e memória social.

\section{Referências}

ALSINA, Miguel Rodrigo. La construcción de la noticia. Barcelona, Buenos Aires, México: Paidós, 1996.

BARCELOS, Caco. 2008. "Repórter: profissão perigo". In: Sheila Kaplan \& Sidney Rezende (orgs.), Jornalismo eletrônico ao vivo. Petrópolis: Vozes. pp. 17-31.

BAUMAN, Zygmunt. Modernidade líquida. Rio de Janeiro: Jorge Zahar Ed. 2011 
BELTRÃO, Luiz. \& QUIRINO, N.O. Subsídios para uma teoria da comunicação de massa. São Paulo: Summus Editorial, 1986.

BERKOWITZ, Dan. Telling the Unknown through the Familiar: Collective Memory as Journalistic Device in a Changing Media Environment. In: NEIGER, M. et al. (Ed.). On media, 2011.

BRUM, Eliane. O Olho da Rua. São Paulo: Editora Globo, 2008.

DINES, Alberto. O Papel do Jornal e a Profissão de Jornalista. (1996), São Paulo: Summus, 2009.

ENNE, Ana Lucia S. (2004). Memória, identidade e imprensa em uma perspectiva relacional. In: Revista Fronteiras - estudos midiáticos, Unisinos, V(2): 101-116.

HALL, Stuart. A Identidade Cultural na Pós-Modernidade . Trad. Tomaz Tadeu da Silva e Guacira Lopes Louro. 10 edição. Rio de Janeiro, DP\&A.2005

HALBWACHS, Maurice. A memória coletiva. São Paulo: Vértice, 1990.

IZQUIERDO, Ivan. Memória. Porto Alegre: Artmed, 1989; 2002.

KARAM, Francisco José Castilhos. Jornalismo, ética e liberdade. São Paulo: Summus, 1997

LAGE, Nilson. Estrutura da Notícia. São Paulo: Ática, 1999.

LE GOFF. Jacques. (2003) História e memória. $3^{\mathrm{a}}$ ed. Campinas: Editora UNICAMP.

LÉVY, P. (1993), As tecnologias da inteligência, Ed. 34, 1993.

MARSHALL, L. O jornalismo na era da publicidade. São Paulo: Summus, 2003

MARQUES DE MELO, José. História do Jornalismo: itinerário crítico, mosaico contextual. São Paulo: Paulus, 2012.

MATHEUS, Letícia Cantarela. 2010 Comunicação, tempo, história: tecendoo cotidiano em fios jornalísticos. Rio de Janeiro: Mauad X; Faperj, 2010

NORA, Pierre. Entre memória e história: a problemática dos lugares. Projeto História, São Paulo, n.10, dez. 1993, p.7-28.

NORA, Pierre. Entre mémoire et histoire: la problématique des lieux. In: Les Lieux de Mémoires. Paris: Gallimard, 2000.

NOBLAT, Ricardo. A arte de fazer um jornal diário. SP: Contexto, 2004.

PALACIOS, Marcos. (2010). Convergência e Memória: Jornalismo, Contexto e História. Matrizes, USP, v. 4, p. 37-50, 2010.

SAPIR, Edward. Comunicação, linguagem e cultura. São Paulo:ECA-USP, 1971. 
SODRÉ, Muniz e FERRARI, Maria Helena. Técnica de reportagem: notas sobre a narrativa jornalística. São Paulo: Summus Editorial, 1986.

TRAQUINA, N. O estudo do jornalismo no século XX. São Leopoldo: Unisinos, 1999.

TRAQUINA, Nelson. (2005) Teorias do Jornalismo. Vol II - A tribo jornalística - uma comunidade interpretativa transnacional. Florianópolis, SC: Insular.

ZELIZER, Barbie. Why memory's work on journalism does not reflect journalism's work on memory. Memory Studies, Sage Publications, v.1, p.79-87, 2008. Disponível em: <http://mss.sagepub.com/cgi/content/abstract/1/1/79> 